 \\ FRELLER, CINTIA COPIT; DIAS FERRARI, MARIAN ÁVILA DE LIMA E \& SEKKEL, MARIE CLAIRE (ORGS.)
}

\section{Educação inclusiva: percursos na educação infantil}

\author{
São Paulo: Casa do Pisicólogo, 2008. 123p.
}

Ani Martins da Silva

\begin{abstract}
A
recente história da educação brasileira, mais precisamente a partir de 1990, tem a narrativa da educação inclusiva como marca. Dispositivos legais, de âmbito federal, estadual e municipal, cada um a seu tempo, passaram a incorporar os princípios de valorização, respeito e atendimento à diversidade humana. De forma progressiva, a temática foi tomada como objeto de investigação acadêmica de dissertações e teses e, concomitantemente, uma avalanche de publicações têm chegado ao público, com enfoques e abordagens teóricas diversas, o que pode indicar, em si, a riqueza do tema como objeto de pesquisa.

Há de se reconhecer, entretanto, que políticas públicas, no campo da educação, não têm dado sinais de efetivos avanços no quadro de exclusão educacional/escolar de parcela significativa das crianças filhas do povo, submetidas a uma perversa exclusão social. A compreensão dos determinantes estruturais e históricos desse quadro, independentemente de outros encaminhamentos analíticos, é condição para o alargamento de nossas reflexões e tomadas de posição política, desencadeadoras de ações coletivas transformadoras, sem espaços para

Professora doutora do Curso de Pedagogia da Universidade Presbiteriana Mackenzie.
\end{abstract}


o imediatismo e superficialidades, pois trata-se da construção de um novo projeto de nação, com a recolocação das políticas sociais, e dentre elas a educação e a cultura, em outros patamares, sem as quais a educação inclusiva tenderá a permanecer mais no plano discursivo, sem possibilidades efetivas de consolidação das conquistas sociais e legais.

Educação Inclusiva: percursos na educação infantil traz em sua primeira parte quatro ensaios teóricos de autores que tematizam a inclusão a partir do locus da escola de Educação Infantil, cujas reflexões e análises, resguardadas as especificidades da faixa etária (0-6 anos), podem ser estendidas às crianças mais velhas frequentadoras da escola pública brasileira. Esse é um dos méritos da obra.

O conjunto dos quatro ensaios - primeira parte - aborda questões importantes que suscitam reflexões que encaminham o leitor para além do espaço da instituição escolar, provocando inquietações e interrogações sobre o tempo presente e futuro das crianças pequenas usuárias de creches e pré-escolas públicas. A segunda parte do livro traz quatro relatos de experiências que, conjuntamente com os ensaios, foram apresentados em seminários, no ano de 2006, organizados pelo Laboratório de Estudos sobre o Preconceito (LaEP) e a pré-escola terapêutica Lugar de Vida, ambos ligados ao Instituto de Psicologia da Universidade de São Paulo.

O primeiro ensaio, de autoria de Marie Claire Sekkel e Ricardo Casco, intitulado "Ambientes inclusivos para a Educação Infantil: considerações sobre o exercício docente", tem como referência teórica fundamental conceitos desenvolvidos por autores da Escola de Frankfurt (Adorno e Horkheimer). Em defesa da construção de uma sociedade mais humana, menos "coisificada", ameaçadora, preconceituosa e marcada pela barbárie, os autores anunciam que "os objetivos desencadeadores das propostas de educação escolar inclusiva têm como foco os alunos com necessidades educacionais especiais e, entre eles, principalmente os deficientes" (p. 26), os frágeis que, nas palavras dos autores, portam signos de adaptação malsucedida. No encaminhamento de suas reflexões, articuladas à formação e atuação do professor, a defesa do exercício da educação crítica, tendencialmente subversiva (Adorno), é tomada como possibilidade de rompimento com a educação instrumental de natureza técnica, que afasta do contato com o outro, com o diferenciado; empreendimento coletivo que implica em conceber a inclusão como processo de reflexão sobre sentimentos e ações de todos os envolvi- 


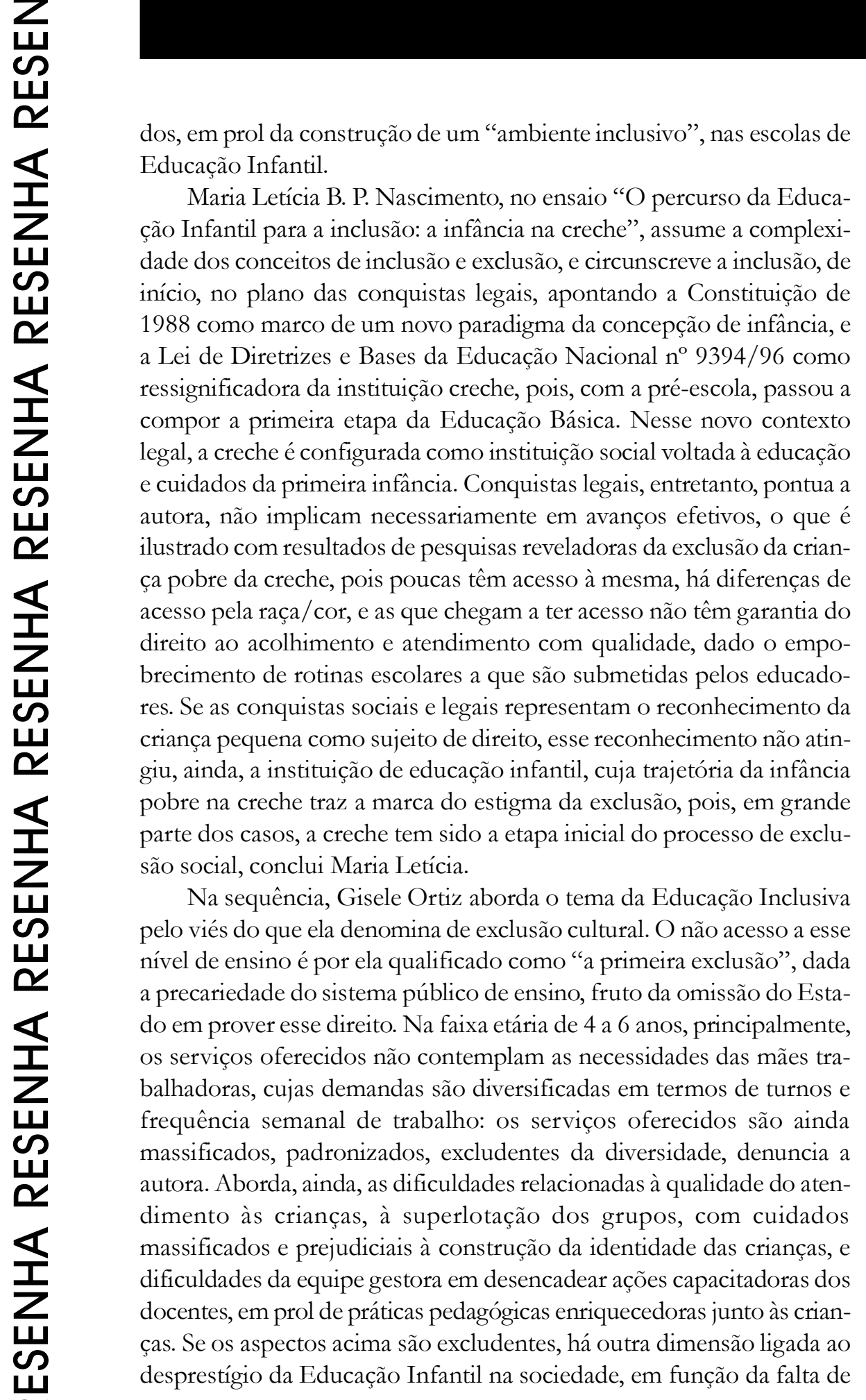

dos, em prol da construção de um "ambiente inclusivo", nas escolas de

Maria Letícia B. P. Nascimento, no ensaio "O percurso da Educação Infantil para a inclusão: a infância na creche", assume a complexidade dos conceitos de inclusão e exclusão, e circunscreve a inclusão, de início, no plano das conquistas legais, apontando a Constituição de 1988 como marco de um novo paradigma da concepção de infância, e a Lei de Diretrizes e Bases da Educação Nacional no 9394/96 como ressignificadora da instituição creche, pois, com a pré-escola, passou a compor a primeira etapa da Educação Básica. Nesse novo contexto legal, a creche é configurada como instituição social voltada à educação e cuidados da primeira infância. Conquistas legais, entretanto, pontua a autora, não implicam necessariamente em avanços efetivos, o que é ilustrado com resultados de pesquisas reveladoras da exclusão da criança pobre da creche, pois poucas têm acesso à mesma, há diferenças de acesso pela raça/cor, e as que chegam a ter acesso não têm garantia do direito ao acolhimento e atendimento com qualidade, dado o empobrecimento de rotinas escolares a que são submetidas pelos educadores. Se as conquistas sociais e legais representam o reconhecimento da criança pequena como sujeito de direito, esse reconhecimento não atingiu, ainda, a instituição de educação infantil, cuja trajetória da infância pobre na creche traz a marca do estigma da exclusão, pois, em grande parte dos casos, a creche tem sido a etapa inicial do processo de exclusão social, conclui Maria Letícia.

Na sequência, Gisele Ortiz aborda o tema da Educação Inclusiva pelo viés do que ela denomina de exclusão cultural. O não acesso a esse nível de ensino é por ela qualificado como "a primeira exclusão", dada a precariedade do sistema público de ensino, fruto da omissão do Estado em prover esse direito. Na faixa etária de 4 a 6 anos, principalmente, os serviços oferecidos não contemplam as necessidades das mães trabalhadoras, cujas demandas são diversificadas em termos de turnos e frequência semanal de trabalho: os serviços oferecidos são ainda massificados, padronizados, excludentes da diversidade, denuncia a autora. Aborda, ainda, as dificuldades relacionadas à qualidade do atendimento às crianças, à superlotação dos grupos, com cuidados massificados e prejudiciais à construção da identidade das crianças, e dificuldades da equipe gestora em desencadear ações capacitadoras dos docentes, em prol de práticas pedagógicas enriquecedoras junto às crianças. Se os aspectos acima são excludentes, há outra dimensão ligada ao 
informação - exclusão cultural - sobre as possibilidades de aprendizagem e desenvolvimento da criança pequena, por meio da apropriação de objetos culturais a ela disponibilizados e mediados pelo professor da Educação Infantil, o que requer desse profissional um outro perfil cultural, pois ele próprio deve ser incluído na cultura, sendo essa o alimento de suas ações mediadoras, sem a qual o reconhecimento e valorização da criança como um construtor de cultura não são possíveis.

No último ensaio, "Igualdade e Diferença”, Rinaldo Voltolini aborda o tema da inclusão, em especial do sujeito com deficiência, circunscrevendo-o no plano da ética e da condição existencial do sujeito que, além dos aspectos sociais, "passa decisivamente por uma implicação subjetiva da parte de todos os envolvidos" ( $p$. 63).

Os termos/conceitos do título do ensaio são sinalizados como os marcadores do eixo paradigmático da política inclusiva, que se diferencia da política anterior, denominada "integrativa". Discorre sobre as diferenças e especificidades de cada um dos modelos e coloca que o mérito da inclusão, em se tratando de deficiências, talvez "tenha sido o de pôr em discussão esse modelo baseado na normalização de funções físicas ou psíquicas ... que no fundo está sem o saber comprometido com uma lógica totalitária" (p. 61). A significação da diferença como sinal de anormali- 
dade (integração) é deslocada para o seu contrário, qual seja, para a significação como normalidade, e não como desigualdade (inclusão).

Enfrentar o paradoxo acima, conciliar diferença e igualdade, implica em um mergulho no inconsciente, pois: "Toda conscientização que não leve em conta o inconsciente corre o risco de produzir falsas mudanças", afirma o autor, ancorado em contribuições lacanianas" (p. 63). Jargões, visões artificiais e "politicamente corretas" transbordam em discursos e produções na área, reveladoras de falsas mudanças, pois reproduzem preconceitos e estigmas com efeitos contrários ao pretendido, dado que mantêm o outro em condições inferiorizadas: "De fato, a piedade é a maneira mais cruel, porque é a forma mais sincera de dizer ao outro que, "de cima", o vemos "por baixo" (p. 62).

O encaminhamento das discussões sobre a educação inclusiva, circunscrita no plano da ética, da subjetividade e da conscientização, como o faz Rinaldo Voltolini, representa a possibilidade de um "retorno a si" por parte de todos os envolvidos com a temática; movimento que desloca do conforto, da posição conservadora de defesa da inclusão restrita a medidas legais e administrativas "que não servem senão para mantermos a consciência mais tranquila, enquanto a mestria se incumbe de pasteurizar os efeitos virulentos da nova proposta" (p. 64).

Acompanhando a linha argumentativa do autor, o mesmo se interroga sobre as consequências advindas da transformação de um paradigma (inclusão) em política pública, de lógica administrativa, que "de-singulariza" a proposta original, transformando-a em "regra de ouro", em "modelo ideal", com universalização das práticas e discursos (p. 66). A resposta à questão está no retorno ao paradigma científico-tecnicista de intervenção científica normalizante. Eis a modernização conservadora, por não promover descontinuidade, mas continuísmo em relação ao modelo anterior: "É por essa razão que seria de se esperar que a perspectiva inclusiva trouxesse em seu bojo também e fundamentalmente uma crítica ao paradigma técnico-científico" (p. 67). Cursos de reciclagem para instrumentalizar o professor, com propostas generalizantes, representam, nesse contexto, a negação das diferenças, bem como a "tipolização" do aluno na escola regular, cuja diferença "será acomodada num sistema que se esforça para acomodá-lo sem nada mudar" (p. 72).

O texto em questão é desafiador, do ponto de vista teórico-prático, e de extrema relevância, pois, como coloca Voltolini: "A questão decisiva para a política inclusiva parece residir na capacidade que ela terá ou não de tornar-se verdadeiramente oposição ao sistema do qual 
ela nasce. Sabemos que isso não é fácil, uma questão é solidária às circunstâncias históricas de sua enunciação" (p. 68).

$\mathrm{Na}$ sequência, temos os relatos de experiências que, assim como os ensaios, são apresentados na mesma ordem em que constam na obra.

Em "Sobre abismos e pontes: entre a inclusão desejável e a possível" Solange A. Emílio e Flávia B. M. Cintra introduzem o relato configurando o binômio inclusão/exclusão como elementos constitutivos de uma mesma relação. A experiência em pauta referese à atuação de profissionais em uma antiga escola da rede privada de ensino, na cidade de São Paulo, que oferta os cursos da Educação Básica. Incluir alunos com necessidades educacionais especiais, na escola particular, de forma ética e responsável, implica, como colocado pelas autoras, em reconhecer dificuldades e limites, com a construção de pontes e sua transposição como estratégia de enfrentamento dos limites que se interpõem entre o desejado e o possível.

No que se refere à instituição escolar, as pontes possíveis são arroladas: preparação e suporte a todos os atores institucionais; dispor de profissionais da comunidade para informar e orientar a equipe escolar sobre as condições dos alunos; compartilhar com o coletivo da escola a busca de soluções; abertura institucional para mudanças.

Cuidados especiais, antes de receber o aluno, devem ser observados, quer quanto às condições da escola para atendê-lo, quanto à concordância do mesmo e de sua família com o projeto pedagógico da escola. A precisão diagnóstica, o histórico e a condição do aluno são colocados como pontos fundamentais ao trabalho, bem como as atividades pedagógicas e avaliações diferenciadas (adaptação), se requeridas pelas condições do aluno, o que pode, por vezes, gerar resistências.

$\mathrm{Na}$ finalização do relato, as autoras afirmam a relevância da criação de um ambiente educacional inclusivo (respeito, acolhimento e solidariedade) e de compartilhamento de dúvidas, angústias e conquistas.

Em "Relato de uma experiência", as autoras Marli dos S. Siqueira, Maria Cecília R. da S. Santos e Silvana L. Yamabuch, integrantes do Núcleo de Educação Inclusiva do Departamento de Orientações Educacionais e Pedagógicas da Secretaria Municipal de Educação de Guarulhos, colocam em pauta as ações da equipe, no ano de 2003, desencadeadas pelo recebimento de um relatório enviado por uma escola da rede, que solicitava a permanência, no estágio III da 


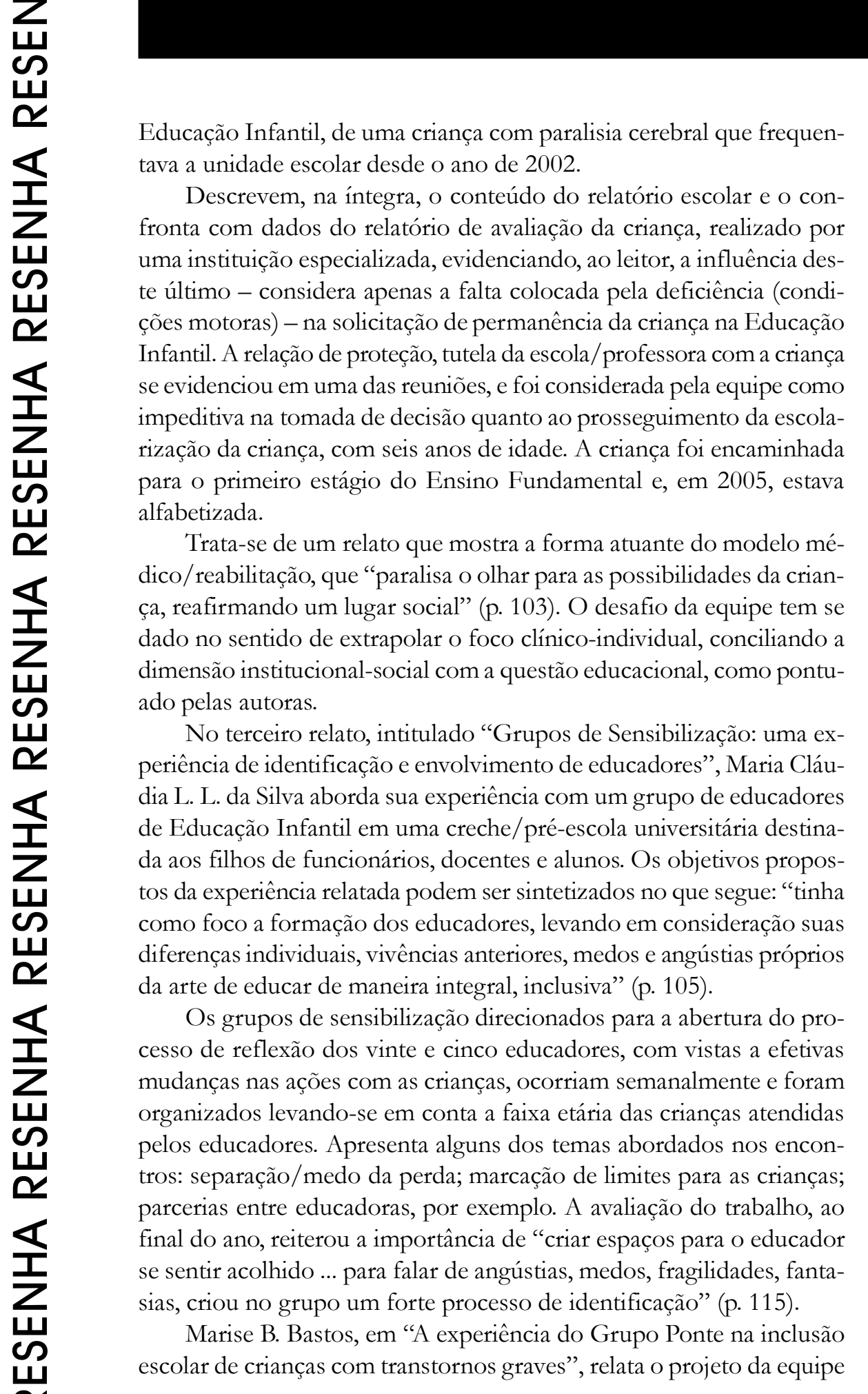




\section{Resenha}

formada por psicólogos escolares psicanalistas e pedagogos, atuantes na Associação Lugar de Vida - Centro de Educação Terapêutica. Trata-se de um trabalho clínico, como afirmado pela autora, cujo objetivo é "criar condições para uma efetiva inserção social dessas crianças gravemente comprometidas" (p. 117). O eixo da educação terapêutica, com atendimento em grupos, como tentativa de promoção do laço social, é a inclusão escolar, o que justifica a ênfase em práticas educacionais dentre as práticas interdisciplinares de tratamento oferecidas às crianças.

O acompanhamento da criança na escola, desde sua inserção, é feito pelo Grupo Ponte, que oferece ao professor o suporte necessário ao trabalho escolar, realizando, ainda, um prévio trabalho com os pais da criança; a criança continua em atendimento clínico na Associação. A interlocução da área da saúde com a educação se estende para além das periódicas visitas às escolas, pois há reuniões mensais oferecidas pelo Grupo, abertas a participações de professores, coordenadores e diretores: "a experiência ... aponta ser possível desenvolver um trabalho com os professores composto pela escuta psicanalítica" (p. 122). "A parceria com os educadores é configurada como peça fundamental nesse trabalho de inclusão escolar como ferramenta terapêutica no trabalho de crianças com distúrbios graves" (p. 123), defende a autora.

A polissemia do termo "inclusão" se evidencia no conjunto da obra, quer se trate dos ensaios teóricos ou dos relatos de experiências. Entretanto, as iniciativas dos seminários, em 2006, que resultaram na publicação da obra, são louváveis, pois o público tem a sua disposição textos importantes e instigantes que se complementam e, principalmente, levam o leitor a se interrogar: afinal, o que é educação inclusiva? Quem é o sujeito da educação inclusiva? Quais as possíveis relações/contradições entre o paradigma da educação inclusiva e os princípios da globalização?

ani.silva@mackenzie.br

Recebido em junho/2010. Aceito em julbo/ 2010. 